\title{
Review on various types of pollution problem in textile dyeing \& printing industries of Bangladesh and recommandation for mitigation
}

\begin{abstract}
This work is aimed at giving emphasis on the present pollution condition in dyeing \& printing industries of Bangladesh due to different textile pollutant. Though the economy of our country is increasing day by day due to medium and small-scale industrial activities, the toxic waste discharge is contributing severe pollution to the environment by this dyeing \& printing industry. The liquid \& solid effluents from different industries are causing a major destruction to the environment, ecology, agriculture, aquaculture and public health since the development of textile industries in the country. So, it is high time to give a break to the pollution and time it out gradually to save the river system. It had become a prerequisite to take required steps to mitigate the pollution problems in each industrial establishment, particularly at dyeing and printing industries that are discharging massive amount of liquid effluent to the rivers every day. Here various types of pollution which is created by the textile dyeing \& printing industries are discussed and some suggestions including raw materials purchasing, Eco-friendly dyeing etc. are point out for mitigation.
\end{abstract}

Keywords: pollution, dyeing \& printing industry, environment, mitigation
Volume 5 Issue 4 - 2019

\author{
Rony Mia,' Md Selim, ${ }^{2}$ Al Mojnun Shamim, ${ }^{1}$ \\ Miraduzzaman Chowdhury, ${ }^{3}$ Suraiya Sultana, ${ }^{4}$ \\ Manijah Armin,' Musfic Hossain,' Rozina \\ Akter,' Shuvo Dey,' Hasnun Naznin' \\ 'Department of Textile Engineering (Wet Processing), National \\ Institute of Textile Engineering \& Research (NITER), Bangladesh \\ ${ }^{2}$ Department of Textile Engineering, Sonargoan University (SU), \\ Bangladesh \\ ${ }^{3}$ Department of Wet Process Engineering, Bangladesh University of \\ Textiles (BUTex), Bangladesh \\ ${ }^{4}$ Key Laboratory of Textile Fiber \& Product, Wuhan Textile \\ University (WTU), China
}

\begin{abstract}
Correspondence: Rony Mia, Lecturer, Department of Textile Engineering (Wet Processing), National Institute of Textile Engineering \& Research (NITER), Savar, Dhaka- I350, Bangladesh, Tel
\end{abstract} +880-19275 I5370, Emailmroni_mia@niter.edu.bd

Received: July 23, 2019 | Published: August 14, 2019

\section{Introduction}

Pollution is the mixture of contaminants in the natural environment that creates adverse effect in environment. Pollution can be formed from chemical substances or misuse of energy such as; noise heat and light Pollutants are the components of pollution. Nowadays different pollutions are creating many hazards to our environment and lives. The pollutants from dyeing, printing and finishing industries have become an alarming issue. Though color is the main attraction of any textile material, it may cause hazards to environment and living beings. We use different dyes for getting required color. In ancient time, natural dye was the main substance for dyeing textile materials. But because of insufficiency of natural dyes and increasing demand of dyed and printed textiles, only natural dyes are unable to fulfill the required demand of dyed and printed textile. So, nowadays a synthetic dye has taken the market of natural dyes. People have started using synthetic dye in every sector of textile dyeing and printing. But the problem is synthetic dye is very toxic and hazardous to our environment. The presence of different dyes like Sulphur, Azoic, indigoids, nitrates, acidic acid, soap, enzymes, complex compounds, heavy metals and certain auxiliary chemicals all are make the textile effluent highly toxic. Thus, the effluent from dyeing and printing industries carry many dyes and other additives which are added during the coloring process. These are to be delivered easily through lakes and rivers especially because they have high water solubility. They may also degrade to form products which are highly toxic and carcinogenic. Thus, these dyes are harmful for living organism. It is most important to save the environment from this effluents. ${ }^{1}$
Though the pollutants of these synthetic dyes are highly toxic, we cannot avoid using these during dyeing considering a very high demand of dyed and printed textiles and it is a major problem. For solving this problem, some mitigation processes must be taken through which we can prevent the surface of normal water by highly toxic dye water. ${ }^{2}$ To solve this problem, firstly it is essential to identify and quantify the chemicals in the waste waters. In Bangladesh, there has a lot of dyeing and printing industries where synthetic dyes are used in a wide range. Several schemes have been proposed in different countries to control the harm of these toxic dyes and chemicals to create better environment and protect the ecosystem from further degradation. So, a developing country like Bangladesh needs to apply their designed policies from the beginning. In our project, we will discuss about these pollution problems which cause harm to our environment and the mitigation processes regarding to the problems.

\section{Literature review}

The textile wet processing industries have an important role in the economic growth as well as environmental sector of a country. The textile dyeing and printing industries has been marked as being one of the world's most offended sectors in terms of pollution. Nowadays different dyes which because different pollution is used in different industries. These dyes affect in 2 major industries of application. They are:

Dyeing industry: Till the midst of $19^{\text {th }}$ century all the dyes used for textile products were produced naturally, until the invention of 
mauvine in $1856 .{ }^{3}$ When the synthetic dyes have invented, after that people started using it in a wide range because these dyes are reasonably price, available in a lot of various colors and they have good color fastness. The textile industry is now producing \& using 1.3 million tons of dyes and pigments per year, where most of them are synthetic as well as toxic. $10-25 \%$ textile dyes are wastage during the dyeing process and $2-20 \%$ is discharged as aqueous effluent. The discharge of dye containing effluent into the water is harmful because of their chemical nature and toxicity. ${ }^{4}$

Printing ink: Heavy metal in the colorants used in printing industry has been reduced significantly in the past 20 years, but many are still in use. For example, titanium oxide, chromate, iron etc. which are used as pigment. These heavy metals pose serious environmental problem because it has the ability to pollute the ground water. ${ }^{5}$

\section{Environmental impact of dyes}

Air pollution: Most processes performed in the wet processing industries produce gaseous emissions. The gaseous air has been identified as the $2^{\text {nd }}$ greatest pollution problem for dyeing and printing industries. Air pollution occurs by the emission of different types of gases such as $\mathrm{CO}_{2}, \mathrm{NO}_{2}, \mathrm{SO}_{2}$ etc. ${ }^{6}$

Water pollution: The dyeing and printing industries use a huge amount of water in their manufacturing processes. The waste water from the dyeing and printing industries is identified as the most polluted water considering the volume generate as well as the effluent composition. ${ }^{7}$ In textile industry 2000000REF tons of dyes are turned to effluent every year during dyeing, finishing and printing operations, due to the inefficiency of dyeing process.

The increased demand of dyed product which is dyed by synthetic dyes produce wastewater after dyeing. This waste water is the main source of pollution problem in recent time. Because most of the industry use conventional waste water treatment plant. The dyes from different sources are stay in the long time in the environment because of their high thermal \& photo stability. ${ }^{8}$

Environmental conditions of Bangladesh's textile industry: The Knitwear and Ready-made garments of Bangladesh's textile industry makes textile earnings is the top position of country. Though, it contributes significant amount of economic growth, it has huge impact on environmental pollution. The main resource of this pollutant is water which is mainly polluted by textile wet processing industries. However, here we are going to discuss the present environmental conditions of textile industries in Bangladesh. The Textile industry of Bangladesh are classified into three main categories, these are Public types, Handloom types and Private types. The most growing sector in our country is private sector. Which are mainly situated Table I Estimated wastewater loads from textile industries in Bangladesh along the rivers bank, because of ensuring easy transportation of raw materials and finished products. For this reason, the effluent from industry directly fall into the river without any purification or treatment of pollutes water. Here, the huge number of risky chemicals such are organic \& inorganic are mixed with the river water because only without effluent treatment. The main industrial locations in our country are in the North Central (NC) region, which means the half of the industries is located here. The 33 percent industries are situated in $\mathrm{NC}$ regions of Dhaka districts and 32 percent are in Narayanganj. The list of main polluting industries is 298 textile mills in 1986, now the list rose to 365 mills according to the recent statistics of DOE. Table 1 gives the summary of environment pollution which is caused by around $50 \%$ of small-scale industries. Here, wastewater discharges $\left(\mathrm{m}^{3} /\right.$ day) and pollution load (BOD $\mathrm{kg} /$ day) are included here. ${ }^{9}$

The Turag River is polluted by the industries which are mainly situated in tongi. The industries always dump the solid waste and liquid effluent into the Turag River. The number of these types of polluting industries is around 20 . The industrial sectors are mostly the dyeing and printing mills. At Savar, the largest industrials zone are situated in old and new EPZ, where the number of industries are around 100 including foreign \& local industries. Here most of them are dyeing and printing industries. For this reason, different types of effluent are entering into the river from these industries, which cause various effects on the land of Savar. These have most farming \& fishing effect near the industrial zones. The industrial effluents are usually discharged into Dhalaibeel which then entered the Bangsai River without any treatment. ${ }^{10}$ Therefore, the highly concentrated heavy metals become harmful to fish and microorganism of the Dhalaibeel. Most of the villages of Savar are now in threating conditions for this wastage water. The Bangladesh Centre for Advanced Studies (BCAS), analysed that EC of Sitalakhya River cross the limit and it was $110 \mathrm{mg} / \mathrm{l}$ - during 1980 but due to unplanned industrialization and harmful agricultural activities, it rises up to $1440 \mathrm{mg} / 1$ in 1998 and TDS increases 216 to $446 \mathrm{mg} / \mathrm{l}$. The water samples from natural sources and deep tube wells situated near industrial areas were collected and analysed for $\mathrm{Na}, \mathrm{K}, \mathrm{Mg}, \mathrm{Ca}, \mathrm{Fe}, \mathrm{Cu}, \mathrm{Cd}, \mathrm{Cr}, \mathrm{Pb}, \mathrm{pH}$, Temperatures, DO, BOD, COD, Total hardness, Total alkalinity, EC, Chloride, TDS, TSS. Most of the units of different parameters were in the out of range. The concentrations of zinc, lead, and cadmium were also found to be higher than the national standards. The area of DND (Dhaka-Narayanganj-Demra) and Narsingdi-Narayanganj projects are also polluted by different pollutants from these industrial areas, because they also do not maintain any rules \& regulations. So, the person who lives in the roadside of these industrial zones faces difficulties each $\&$ every day. They do not do their farming activities as desired they want. ${ }^{11}$

\begin{tabular}{lllll}
\hline Industry & Public(num) & Privet(num) & Wastewater Discharges ( $\mathbf{m}^{3} /$ day) & Pollution load (BOD kg/day) \\
\hline Textiles & 20 & 482 & 40,000 & 26,000 \\
\hline
\end{tabular}

\section{Method \& metholodogy}

\section{Purposes of the significant study}

1. To study the different forms of pollution in Bangladesh's Textile Wet Processing Industries.

2. To analyses the different pollution prevention steps in different section.
3. To discuss Eco-Friendly dyeing techniques for pollution prevention.

4. To study the policies of Textile dyeing \& printing Industries of Bangladesh against Pollution Prevention.

Pollution: Pollution is the introduction of different contaminants of natural environment which causes various harmful, discomforts, instability effect to the ecosystem. It can be in different form of 
chemical or physical substances such are water, noise, gaseous or light. The different elements of pollution are called pollutants, these can be occurred naturally or form external pressure. Mainly pollution is classified into point sources and nonpoint sources. ${ }^{12}$

Forms of pollution: There are different types of pollution around the world, in the different sectors of industries. In general pollution mainly divided into following categories
a. Water Pollution
b. Air Pollution
c. Noise Pollution
d. Soil Contamination
e. Light Pollution
f. Littering
g. Radioactive Contamination
h. Thermal Pollution
i. Visual Pollution

Pollution in wet processing industries: The pollution of textile wet processing industries are mainly into following category among all of the forms.
i. Water pollution.
ii. Air Pollution
iii. Noise \& Vibration pollution.

Here, water pollution is more significant compared to other pollution (Figure 1).

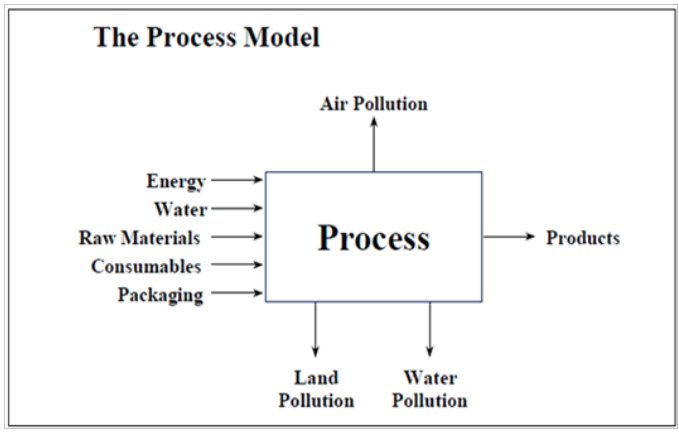

Figure I Process model of pollution.

Water pollution: Water is consumed many more by textile industry. The percentage of water consumption is $3.2 \%$ for various processes such as Desizing, Bio-Polishing, scouring, bleaching, mercerizing, dyeing, printing and other finishing process in total water consumption. After using the water in different processes, it mixed with various dyes, chemicals or other auxiliaries, which are then contaminated $\&$ creates water pollution. In recent times, the use of synthetic dyes, synthetic fibers, and synthetic finishes are increased rapidly in textile industry (Figure 2).

Sources of water pollution: Water pollution can be result of various sources. Here in the following Table 2 an idea is presented on the source of water pollution in textile wet processing industry.

Air pollution: Ambient air is a mixture of gases i.e. 78\% nitrogen, $20 \%$ oxygen, about $1 \%$ argon, $0.03 \%$ carbon dioxide and several minor gaseous elements such as neon, helium, methane, krypton etc. Air pollution is defined by the increased of particulate matter or gases in the composition of air which is released by the industry. The particulate matter can be mixed with air in the different form, such as fine dust, aerosols, fumes and gases (Figure 3).

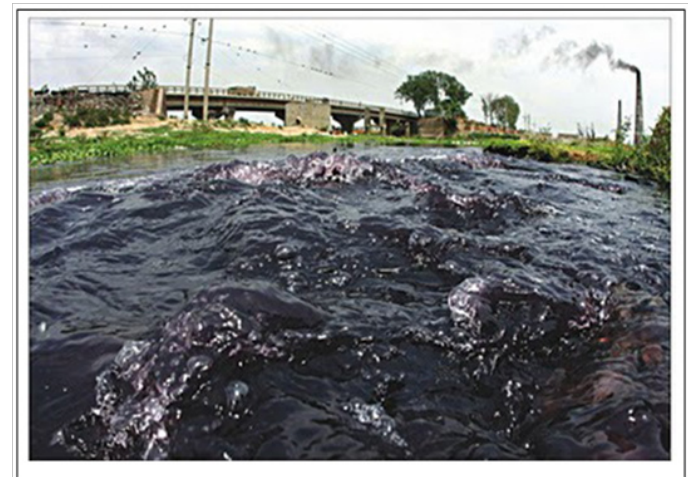

Figure 2 Waste water.

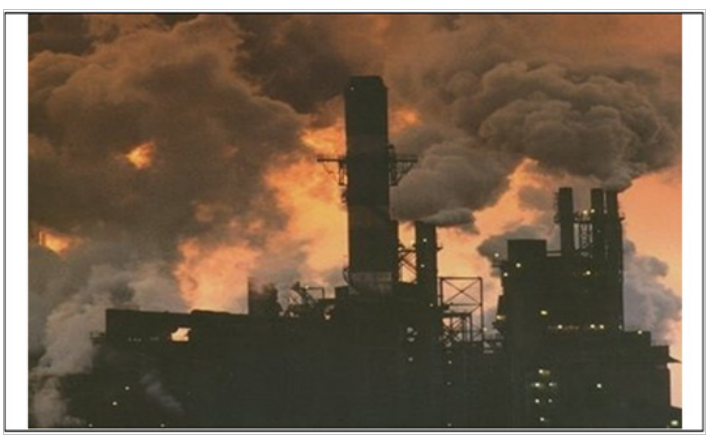

Figure 3 Air pollution.

Sources of air pollution: Different sources of air pollution mainly generated in weaving \& spinning industry. Dust particles are available in yarn \& fabric manufacturing unit. Though air pollution is little bit in wet processing industry, but it creates harmful effect on environment. The main source of air pollution in dyeing \& printing industries is steam generation by coal and water. When the steam is generated, it produces carbon, carbon dioxide, carbon monoxide and Sulphur, which again cause air pollution.

Hazards of air pollution: Air pollution has hazardous impact on human being and animals. Air pollution results to mortality to eye, respiratory problems, irritation, diminishing visibility, persistence of fog etc (Table 3).

Major Environmental Problem for the Wet Processing Industries: It is important for each source of waste to be carefully identified for a textile processing operation. This can be done by-1. Inventory control and knowledge of potential pollutants in purchased products. 2 Process analysis.

Specific types of pollutants that will be considered are:
A. BOD.
B. Acidity/Alkalinity $/ \mathrm{p}^{\mathrm{H}}$.
C. Toxicity.
D. Air Emissions
E. Metals. 
Table 2 Pollution source table

\begin{tabular}{|c|c|c|}
\hline Process & Possible pollutants & Nature of effluent \\
\hline Desizing & $\begin{array}{l}\text { Starch, glucose, CMC, PVA, resins, fats \& waxes not exert } \\
\text { a high BOD }\end{array}$ & $\begin{array}{l}\text { Very small volume, High BOD:( } 30 \%-50 \% \text { of total) } \\
\text { CMC \& PVA }\end{array}$ \\
\hline Scouring & $\begin{array}{l}\text { Caustic Soda, waxes \& grease, soda ash, sodium silicate \& } \\
\text { fragments of cloth }\end{array}$ & $\begin{array}{l}\text { Small volume, Strongly alkaline, dark colour, high BOD: } \\
\text { ( } 30 \% \text { of total) }\end{array}$ \\
\hline Bleaching & $\begin{array}{l}\text { Hypochlorite, Chlorine, caustic soda, hydrogen peroxide, } \\
\text { acids }\end{array}$ & $\begin{array}{l}\text { Small volume, Strongly alkaline, Low BOD: ( } 5 \% \text { of } \\
\text { total) }\end{array}$ \\
\hline Mercerization & Caustic soda & $\begin{array}{l}\text { Small volume, strongly alkaline, low BOD: (less than I\% } \\
\text { of total) }\end{array}$ \\
\hline Dyeing & $\begin{array}{l}\text { Dyestuff, mordant and reducing agents like sulphides, acetic } \\
\text { acid \& soap }\end{array}$ & $\begin{array}{l}\text { Large volume, strongly coloured, fairly high BOD: }(6 \% \\
\text { of total) }\end{array}$ \\
\hline Printing & $\begin{array}{l}\text { Dyes, Starch, gums oil, china clay, mordant, acid \& metallic } \\
\text { salts }\end{array}$ & Very small volume, oily appearance, fairly high BOD. \\
\hline Finishing & Traces of starch, tallow, salts, special finishes etc. & Very small volume, less alkaline, low BOD \\
\hline
\end{tabular}

Table 3 Source \& effect of pollution

\begin{tabular}{lll}
\hline Pollutants & Effects of human being & Sources \\
\hline Sulphur dioxide & Irritates respiratory system and causes bronchitis & Boiler flue gas, rayon plant etc. \\
Aldehydes & Irritates all parts of respiratory system & Polyester plant \\
Chlorine & Causes lung irritation and irritation in eyes & Processing house \\
Carbon dioxide & $\begin{array}{l}\text { Deprives body cells of oxygen and cause unconsciousness } \\
\text { by CO combining with haemoglobin }\end{array}$ & Boiler house \\
\hline
\end{tabular}

Pollution prevention: The steps which describe the activities that minimize the amount of pollution generated by a process, whether it is consumer consumption, driving or industrial production is called pollution prevention (P2). Although there is wide agreement that source reduction is the preferred strategy, sometimes some of the professionals identified the terms pollution prevention is as recycling or reuse. Pollution prevention encompasses more specialized subdisciplines including green chemistry and green design. ${ }^{13}$

Possible pollution mitigation techniques in dyeing industry: Pollution in dyeing industry can be minimized by following consideration.

Purchasing policy for raw materials: The textile company should communicate with suppliers having less-polluting raw materials. The industry will buy those chemicals which have less impact on environment.

Maintaining low-liquor ratio dyeing: The amount of chemical used depends on bath ratio. When the dyeing industry use less bath ratio, then less amount of chemicals is required in the dye bath. For that reason, environment is less polluted.

Salt management: Although salt is cheap, effective and has very low toxicity, it has to be used with optimum dosage for each individual for each dyeing. For this reason, the dyes which exhaust minimum salt in dyeing is recommended, e.g. Cibachrome LS dye.

Dye bath temperature: To reduce the pollution from excess consumption of dyes, dye bath temperature should be controlled. If dye bath is heated by direct steam, the heating should be gently, to avoid overflowing and subsequent loss of dye bath solution, which causes pollution.

Reuse of dye baths: If we use the dye bath again after using this, then an amount of chemicals is stayed in the dye bath. But if we wash it, the chemicals are going through the wastage tank and make pollutant. So, Reuse of dye bath can be the another options for pollution mitigation.

Substitution of harmful dyestuffs: Different types of Black dyeing are create more effluent after dyed a material. So, this is recommended to avoid these types of dyes which are more toxic and create more pollutant in dyeing process. In vat dyeing, potassium dichromate should be replaced by peroxides or periodate's for pollution Mitigation for its toxic \& hazardous nature. ${ }^{14}$

Minimizing machine cleaning: In dyeing operations, start-ups, stop offs, and colour changes cause intensive cleanings and pollution in effluents. For minimizing effluents generation, the same color is repeatedly run in the same machine or group colours (red, yellow, blue) and then run the dyes within one colour family from lighter to darker values and from brighter to duller chromes.

Handling of powder dyes: The powder dye should be handling very carefully. Because powder dye create many more dust when it transferred from one place to another. After that, it creates many more disease in workers. So, proper handling is necessary for powder dyes.

Banned dyes: Due to toxicity, mutagenic or carcinogenic properties of dyes, some of the dyes should be banned for used. These dyes release amines during processing that are hazardous. So, should not use this dye in industry. These dyes are listed in the following Table 4.

Possible pollution mitigation techniques in printing industry: Here, some of the recommendations for pollution mitigation in printing are described:

a. The printing pastes which are not used in the printing operation, these will be collected in the systems and it should be reuse again for printing to reduce the pollution.

b. The use of urea in printing with reactive dyes should be reduced 
by (or in combination with) other techniques (e.g. pre- wetting of fabric) so that the nitrogen emissions do not increase. The printing paste should contain no more than $30 \mathrm{gm}$. of urea $/ \mathrm{kg}$ of textile.

Table 4 Banned dyes ${ }^{15}$

\begin{tabular}{|c|c|c|c|}
\hline No & Banned amine & No & Banned amine \\
\hline I & 4- Aminodiphenyl & II & 3,3-Dimethylbenzidine \\
\hline 2 & Benzidine & 12 & 3,3-Dimethoxybenzidine \\
\hline 3 & 4- Chloro -o- toluidine & 13 & $\begin{array}{l}\text { 3,3-Dimethyll-4,4 } \\
\text { diaminodiphenylmethane }\end{array}$ \\
\hline 4 & 2- Naphthylamine & 14 & p-kresidin \\
\hline 5 & o-Aminoazotoluidine & 15 & $\begin{array}{l}\text { 4,4 Methyene- bis- } \\
\text { (2-chloraniline) }\end{array}$ \\
\hline 6 & 2- amino-4 nitroluene & 16 & 4,4 Oxydianiline \\
\hline 7 & p-Chloraniline & 17 & 4,4 Thiodianiline \\
\hline 8 & 2,4- Diamonoanisol & 18 & o-Toluidine \\
\hline 9 & 4,4- Diaminodiphenylmethane & 19 & 2,4-Toluylendiamine \\
\hline 10 & 3,3-Dichlorobenzidine & 20 & 2,4,5-Trimethylaniline \\
\hline
\end{tabular}
are:

Some approaches to eliminate or replace urea in cellulose printing

i. Adoption of two-phase flash printing.

ii. Complete or partial substitution of urea with an alternative Chemical like Methaxyl FN-T.

iii. Mechanical application of moisture to printed fabric prior to entering the steamer.

iv. Full or partial substitution of gum thickening by emulsion thickening in textile printing.

v. Replacement of the use of white spirit kerosene by waterbased system.

vi. Minimizing the use of copper and chrome salts to the extent possible.

vii. Avoiding use of solvent-based pastes in pigment printing.

viii. Recovery of acetic acid, which is used to bond the two components of azoic dyes.

ix. The use of pigments, which give improved absorption and lower effluents for reducing COD.

x. Some of the pigments are suspected to have toxic/carcinogenic properties, and these are listed and the safer alternatives corresponding to each pigment is given.

xi. Different types of Biodegradable natural thickening auxiliaries should be chosen.

xii. Printing screens should be replaced by non-contact techniques (e.g. ink-jet printing). ${ }^{16}$

\section{Eco-friendly dyeing}

Dyeing process (Figure 4)

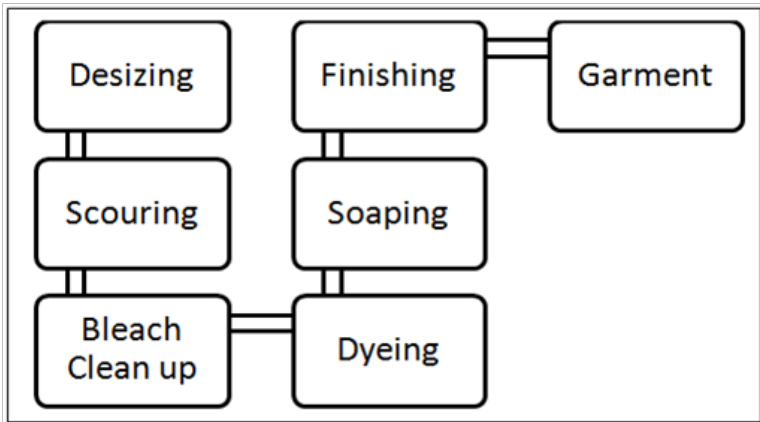

Figure 4 Eco-friendly dyeing.

\section{Desizing with biocatalyst}

\section{Advantages:}

1. Less chemicals involved

2. Eco-friendly

3. Efficient in wide range temperature

4. Specific, no damage to cellulose fibres

5. Better strength retention

6. Softer fabric feel

7. Shorter process time

\section{Scouring (Figure 5)}

\section{Advantages of bio scouring:}

a) Eco-friendly (less harsh chemical-caustic soda)

b) Less rinse water needed

c) Reduce effluent load

d) Reduce water consumption

e) Save energy

f) Save cost

g) Fully retain cellulose structure (Table 5)

\section{Bleach clean up:}

A. Removal of $\mathrm{H}_{2} \mathrm{O}_{2}$ residual to ensure levelled dyeing

B. Bleach Clean Up Alternatives

\section{Advantages of using biocatalyst:}

i. Save water-No rinsing required.

ii. Save energy-No need to hot rinse, cold rinse, and hot rinse.

iii. Save time-maximum $10 \mathrm{~min}$ to complete the process.

Cold pad batch (CPB) dyeing: A more environmentally sound and higher quality dyeing method (Figure 6). 


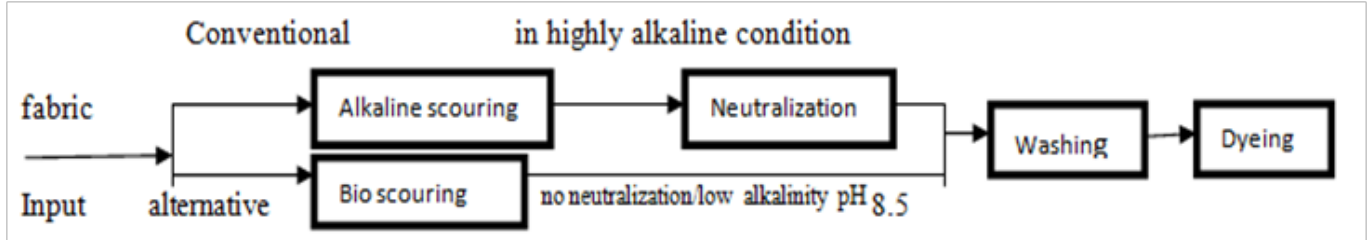

Figure 5 Scouring process of eco-friendly dyeing.

Table 5 Comparison between alkaline scouring \&bio scouring

\begin{tabular}{lll}
\hline Measurement & Bio scouring & Alkaline scouring \\
\hline $\mathrm{pH}$ & $8-9.5$ & $13-14$ \\
Temperature & $50-600 \mathrm{c}$ (extract at 75-950c) & $95-1000 \mathrm{c}$ \\
Residual pectin & $22-30 \%$ & $10-15 \%$ \\
Weight loss & $<1.5 \%$ & $4-10 \%$ \\
$\begin{array}{l}\text { Wet ability, drop } \\
\text { test }\end{array}$ & $<1$ second & $<1$ second \\
$\begin{array}{l}\text { Brightness } \\
\text { increase }\end{array}$ & $+1-5 \%$ points & $+5-10 \%$ points \\
Bleach ability & Same & Same \\
\hline
\end{tabular}

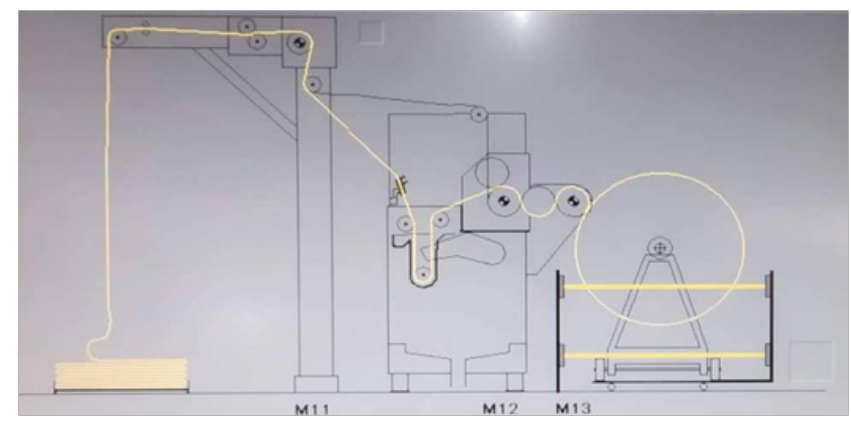

Figure 6 Dyeing process of Cold Pad Batch (CPB).

Process description: Total volume of pad-trough 10/15litres per metre of width of fabric (example 2 metres; volume 20 to 30 litres)

1. Immersion time $1.5 \mathrm{sec}$

2. Bath temperature $25-30^{\circ} \mathrm{C}$

3. Pick up $70-80 \%$

4. Fabric speed such as the time to completely renew the trough should not exceed 10 minutes

\section{Advantages of cold pad batch dyeing:}

a. Simplicity in process of dyestuff application

b. Reduction in water consumption by 50 to $80 \%$

c. Reduction in energy consumption by up to $60 \%$

d. Reduction in chemical costs, other than dyestuff, by up to $50 \%$ due to elimination of salt and reduction of alkali requirements

e. Reduction in labour costs by 40 to $60 \%$

f. Minimum fabric abrasion

g. Excellent shade reproducibility from lot to lot

h. So, we tried to give a brief idea on eco-friendly dyeing as a modern pollution free greener technology for textile wet processing technology. ${ }^{17}$

\section{Benefits of pollution prevention:}

i. Loss reduction.

ii. Reduction of chemical, water and energy consumption, thereby resulting in savings, sometimes even increased production.

iii. Reduced liability for waste produced.

iv. Improved compliance with regulations.

v. Cleaner and healthy working environment.

\section{Limitation of pollution prevention:}

a) Pollution prevention research is an ongoing case where the total success is not achieved.

b) The eco-friendly materials are not that much available.

c) The available materials are quite expensive.

d) The quality of the product may be not desirable.

e) Proper awareness increasing among the people is a hard task.

Our ideas on pollution prevention: By assessing the literature, we see that the largest waste stream from most textile mills involved in washing, bleaching, and dyeing is wastewater. Textile mill wastewater is often contaminated with process chemicals (dye, salt, bleach, detergent, etc.), oil, and energy from hot water discharges. As a result, wastewater discharge permit limits, such as BOD (Biological Oxygen Demand), COD (Chemical Oxygen Demand), aquatic toxicity, and metals content, are often difficult to meet. According to a research in Thailand, water usage in a typical mill can easily top 40,000 gallons per day costing more than $\$ 30,000$ annually in water and sewer fees.

Another area where waste can be reduced is in chemical mixing. Adding excessive chemicals to recipes will increase cost and may cause quality problems. For complete exhaustion, Different dye mixtures have required different amounts of salt. There are many opportunities to reuse wastewater in a textile mill. For example, final rinse water from dyeing can be used as make-up water for the dye bath. Final rinses from scouring and bleaching may be used for makeup water in desizing. Wastewater from many sources may be suitable for washing process equipment and floors (after sweeping or another dry clean-up). As an example, we may add, in Viyellatex Group they do not discharge the treated effluent into the sewerage or local pond or river rather than they use that water as flash water in the toilet. ${ }^{18}$ This type of little steps can help to reduce the wastage of water where the process is very easy but the only lacking is a noble intention. Some mills have reduced operating costs substantially by installing water reuse systems.

Air pollution is also a concerning factor; where discharged polluted air infecting our environment. In case of releasing air into 
the environment, filtering is a possibility where the harmful gases like sulphur, Carbon mono oxide, ozone can be extracted. In some process steps we use harmful solvents, oils, chemicals which can degrade the air quality into dangerous level. Here more bio friendly option is suggested.

Noise pollution although not a big option in textile wet processing industries but in power generator or in boiler noise level can be out of range, silencer in this case may be an option, also according to the safety factor of the employee's ear plug use is also suggested.

\section{Discussion \& conclusion}

This work was based on the practice of pollution prevention in textile dyeing \& printing industries of Bangladesh. Most of the factories of Bangladesh do not follow the rules \& regulations. So, strict regulation is necessary also the Government must ensure that whether the industries are following the rules or not. The industry produce waste and treatment of this waste is regularly necessary. Also, further initiative is necessary, because not only water pollution, but also air pollution, noise pollution, soil pollution these are increasing day by day. Action against this is very necessary but unfortunately it is very much absent in textile dyeing \& printing industry. In the finale, we may say that the action of wet processing industries seems to be effective, but the real scenario is different where more initiative is must necessary in textile dyeing \& printing industries of Bangladesh.

\section{Acknowledgments}

None.

\section{Funding}

None.

\section{Conflicts of interest}

The authors declare that they have no competing interests.

\section{References}

1. Shafi S. Environment pollution. New Delhi: Atlantic publisher \& distributer; 2005.

2. Hassaan MA, Nemr AE. Health and environmental impacts of dyes: mini review. American Journal of Environmental Science and Engineering. 2017;1(3):64-67.

3. Iqbal M. Textile dyes. Karachi: Rehbar Publishers; 2008.

4. Shenai DV. Chemistry of dyes and principles of dyeing. Mumbai: Sevak Publications; 1993.

5. Shenai DV. Technology of printing. Mumbai: Sevak Publication; 1990.

6. Vallero D. Fundamentals of air pollution. USA: Elsevier; 2014.

7. Nesaratnam ST. Water pollution Control. Wiley Online Library; 2014.

8. Sakamoto M, Ahmed T, Begum S, et al. Water Pollution and the textile industry in Bangladesh: flawed corporate practices or restrictive opportunities? Sustainabilty. 2019:1-14.

9. Textile industries in Bangladesh: a rising environmental degradation down the drains. Dhaka: Textile Today; 2008.

10. Fancy bear environment global programm. 2019.

11. Slide Share.

12. Pollution. Wikipedia.

13. Epa U. Pollution prevention. 1996.

14. Achwal W. Environmental aspects of textile chemical processing (part I). Colour Age; 1990.

15. World dye variety.

16. Jones S, Snowden-Swan L, Meyer P, et al. Fast pyrolysisand hydrotreating: 2014 state of technology R\&D and projections to 2017. U.S. Department of Energy; 2015.

17. Eco friendly dyeing in Matex. 2007.

18. Viyellatex. 